This item was submitted to Loughborough's Research Repository by the author.

Items in Figshare are protected by copyright, with all rights reserved, unless otherwise indicated.

\title{
Does activity-related social support differ by characteristics of the adolescent?
}

PLEASE CITE THE PUBLISHED VERSION

http://dx.doi.org/10.1123/jpah.2012-0054

\section{PUBLISHER}

(c) Human Kinetics

\section{VERSION}

AM (Accepted Manuscript)

\section{PUBLISHER STATEMENT}

This work is made available according to the conditions of the Creative Commons Attribution-NonCommercialNoDerivatives 4.0 International (CC BY-NC-ND 4.0) licence. Full details of this licence are available at: https://creativecommons.org/licenses/by-nc-nd/4.0/

\section{LICENCE}

CC BY-NC-ND 4.0

\section{REPOSITORY RECORD}

Edwardson, Charlotte L., Trish Gorely, Hayley Musson, Rebecca Duncombe, and Rachel A. Sandford. 2019. "Does Activity-related Social Support Differ by Characteristics of the Adolescent?". figshare. https://hdl.handle.net/2134/19800. 
Title: Does Activity-Related Social Support Differ by Characteristics of the Adolescent?

Brief Running Head: Activity-Related Social Support

Manuscript Type: Original Research

Key Words: Support, modelling, logistic, adolescents

Abstract: 192

Main Text: 2988

Date of Submission (R1): 27/07/2012 


\begin{abstract}
Background: Previous research has shown a positive relationship between activity-related social support provided by parents and peers, and adolescents’ physical activity. However, more information is needed on whether activity-related social support differs by sociodemographic characteristics. The purpose of this study was to investigate differences in activity-related social support in a sample of adolescents, by characteristics such as age, gender, socio-economic status, ethnicity and physical activity level and to determine which characteristics are the most important predictors of activity-related social support. Methods: 578 boys and 588 girls (11-14 years) provided information on demographic factors, physical activity and activity-related support. ANOVA, correlations and multiple regression were performed to address the purposes of the study. Results: Boys, White British, younger, more physically active and high SES adolescents perceived more support for physical activity. Age predicted all types of support excluding peer support; ethnicity predicted mother logistic support and sibling support; gender predicted peer support, father explicit modelling and father logistic support; and SES predicted mother and father logistic support. Conclusions: Families and peers of adolescents who are female, from Black and Minority Ethnic groups, older, of low-SES and less active should be targeted for intervention.
\end{abstract}

Key Words: Support, modelling, logistic, adolescents 


\section{Introduction}

In spite of the growing scientific knowledge on the benefits of active lifestyles for the health and well-being of young people $\mathrm{e}^{1,2}$, current data show that many young people are not meeting the national physical activity recommendations of achieving at least 60 minutes of moderate intensity physical activity each day ${ }^{3}$. For example, self-reported data from the most recent Health Survey for England suggests that only 32\% of boys and $24 \%$ of girls achieved the recommended levels of physical activity. Furthermore, research has shown that the percentage of young people meeting the recommendations declines precipitously with age ${ }^{4,5}$. This decline in physical activity has not only been demonstrated from childhood to adulthood but even in the short time from childhood to adolescence ${ }^{6,7}$. This underscores the need for physical activity intervention programmes to prevent the decline in physical activity that occurs during adolescence.

An important prerequisite to designing and implementing physical activity interventions is to understand the factors that influence adolescents' physical activity. Activity-related social support might promote and facilitate physical activity among adolescents ${ }^{8}$. Social support has been defined in numerous ways, but generally refers to any behaviour that assists an individual in achieving desired goals ${ }^{9}$. The conceptual framework for specifically studying social support and involvement in physical activity includes tenants from the social cognitive theory, whereby a person can learn from other people (e.g., family, friends) not only by receiving reinforcements from them to participate in physical activity but also through observing them (modelling) engaging in physical activity ${ }^{10}$. There are multiple sources (i.e., family, parents, siblings, friends, other relatives) of social support that young people may be exposed to but parents are considered to be one of the most important teachers and social referents throughout childhood and adolescence ${ }^{11}$. Parents teach skills and introduce beliefs 
that can help shape important attitudes and behaviours associated with physical activity participation. Parents model active behaviours for their children, engage in activities with them, encourage participation and provide logistical support in terms of transportation, enrolment and fee paying, and these types of support have all been shown to be associated with adolescents’ physical activity ${ }^{12-14}$. Siblings are another source of social support that have the potential to influence physical activity behaviour. Siblings are a significant part of family life during childhood but their potential influence has received little attention.

Those groups who influence adolescents tend to change over time and as children move into adolescence they spend increasing amounts of time with friends thus enhancing the potential for peer influence over their behaviour ${ }^{15}$. The peer group influence on physical activity could conceivably function in a numbers of ways: 1 ) adolescents mutually influence each other into starting physical activity; 2) an adolescent may engage in physical activity because his/her friend is already active; 3) friendships are established between adolescents who are already engaged in physical activity; 4) adolescents provide emotional support such as encouragement to be physically active; and 5) adolescents provide logistical support such as sharing transport and equipment. Previous research has shown a positive relationship between activity-related social support from peers and young people’s physical activity ${ }^{16-18}$.

It therefore appears that interventions could target parents and adolescents’ peers as providers of support to increase physical activity levels. However at present, it is unclear whether the perceptions of support differ by sociodemographic characteristics. A small number of researchers have examined gender, age and physical activity level differences in social support and have indicated that boys report higher parent and peer support than girls ${ }^{17}$, activity support decreases across adolescence ${ }^{17}$ and adolescents who are more active report 
higher levels of activity support ${ }^{8,17}$. However, this research is limited in number and information on how activity support levels differ by socioeconomic status (SES) and ethnicity is lacking, albeit there is qualitative research with young children in this area that suggests that these factors are important ${ }^{19,20}$. Furthermore, SES and ethnicity differences in levels of physical activity have been reported ${ }^{6}$ therefore it is plausible to think that differences in activity support may also be present.

Identifying groups of adolescents that lack support for physical activity is important in providing target groups for interventions. Therefore, before designing and implementing support-based intervention programmes, more information is needed on whether activity support is equal among all youth. The purpose of this study is to confirm and build on the current literature on the variation in adolescent perceived activity-related social support by characteristics such as age, gender, ethnicity, SES and physical activity level. This study sought to answer two specific questions; 1) are there differences in the amount of perceived activity-related social support by age, gender, SES, ethnicity and physical activity level of the adolescent; and 2) which characteristics (age, gender, SES, ethnicity) are the most important predictors of activity-related social support.

\section{Methods}

\section{Participants and design}

A multi-ethnic sample of secondary school students was recruited from five schools in the East Midlands of England. Schools were recruited based on their SES which was calculated using the 2007 Indices of Multiple Deprivation (IMD) ${ }^{21}$, which is described below, and percentage of Black and Minority Ethnic (BME) pupils. Students in year groups 7 and 9 were invited to participate in the study. Before participation, consent was sought from parents and 
adolescents provided assent. Once consent was obtained, pupils completed a questionnaire under the supervision of class teachers and/or trained researchers. The final sample of participants consisted of 578 boys and 588 girls aged 11-14 years. Study procedures were approved by the Ethical Advisory Committee of Loughborough University.

\section{Questionnaire Items}

Ethnicity and SES. Ethnic group was reported by the adolescent and/or provided by the school. SES was calculated using the 2007 Indices of Multiple Deprivation (IMD), which were derived from each child's home postcode. The IMD is a measure of compound social and material deprivation, calculated from a variety of data including income, employment, health, education, and housing. For the calculation of IMD, England is divided into 32,482 small areas which are ranked according to their deprivation score ${ }^{21}$.

Physical Activity. Physical activity was assessed with the question 'During the past 7 days, on how many days were you physically active for a total of at least 60 minutes per day? (Add up all the time you spend in any kind of physical activity that increases your heart rate and makes you breathe hard some of the time), ${ }^{22}$. This question was taken from the Youth Risk Behaviour Surveillance Questionnaire and has demonstrated good reliability (kappa statistics $41.1-84.8 \%$ ), when delivered 15 days apart ${ }^{23}$, and validity ${ }^{24}$.

Physical Activity Support. The Activity Support $\mathrm{Scale}^{8}$ is a self-report questionnaire assessing: (a) general familial support (3 items, e.g., 'my family and I do active things together'); (b) peer support (5 items, e.g., 'my friends think it is important to be physically active’); (c) sibling support (5 items, e.g., 'my sibling and I like to do active things together'); and (d) maternal (8 items) and paternal (8 items) support. These latter items reflect how much 
support the mother or father provided in each of the following domains, explicit modelling (5 items, e.g., 'my father often exercises or does something active') and logistic support (3 items, e.g., 'my mother takes me to places where I can be physically active'). All items were presented on a four point Likert scale ranging from strongly disagree to strongly agree. Previous studies have demonstrated adequate psychometric properties for the Activity Support Scale ${ }^{8}$ and in the current study Cronbach's alpha coefficients ranged from 0.72 0.88 for the subscales indicating satisfactory internal consistency.

\section{Data Analyses}

All analyses were conducted using PASW Statistics version 18. All variables were checked for normality and visual inspection of these histograms and the Shapiro-Wilk test confirmed that they were normally distributed. In order to examine differences in activity-related social support several groups were created: 1) younger and older adolescent groups were created by grouping participants by their school year (i.e. adolescents in school year 7 were grouped as younger adolescents and adolescents in school year 9 were grouped as older adolescents); 2) Two ethnic groups were created by grouping White British adolescents (group 1) and Black and Minority Ethnic (BME) adolescents (group 2); 3) Low and high SES groups were created by dividing 32,482 by three to create low, middle and high SES groups. All participants who fell into the middle SES group were removed from analysis ( $\mathrm{n}=187)$; and 4). Two physical activity groups were created by grouping those who achieved 0-4 days of at least 60 minutes of physical activity (i.e., those not meeting the physical activity guidelines) and those who achieved 5-7 days of at least 60 minutes of physical activity (i.e., those meeting the physical activity guidelines). 
To address question one (are there differences in the amount of perceived activity-related social support by age, gender, SES, ethnicity and physical activity level of the adolescent?), ANOVA was performed to examine differences in mean levels of activity-related social support by gender, age, SES, ethnicity and physical activity level. To address question two (which characteristics (age, gender, SES, ethnicity) are the most important predictors of activity-related social support?), correlations were used to explore simple relationships between variables and following this any significant variables were entered into a multiple regression analysis to determine which of the four characteristics (gender, age, SES, ethnicity) were important predictors of activity-related social support.

\section{Results}

In total, 1166 adolescents were included in the analysis, of which 578 were boys and 588 were girls (mean age $=12.6$ and 12.8 years respectively), 66\% were White British, 59\% were low SES and 54\% fell into the 'those not meeting the physical activity guidelines' category (achieving 0-4 days of at least 60 minutes of physical activity). Table 1 presents mean sources of activity-related social support by adolescent characteristics.

\section{Differences in activity-related social support}

Table 1 also highlights differences in activity-related social support between groups and addresses question one. Significant gender differences were found for father explicit modelling, mother logistic support, father logistic support and friend support with boys perceiving more support from these sources than girls. Significant ethnicity differences were found for mother logistic support, father logistic support and sibling support with White British adolescents perceiving more support from these sources than BME adolescents. Significant SES differences were found for mother and father logistic support and sibling 
support with high SES adolescents perceiving more mother and father logistic support than low SES adolescents and low SES adolescents perceiving more support from siblings than high SES adolescents. Significant age and physical activity level differences were found for all sources of support with younger adolescents and the most active adolescents perceiving more support than older adolescents and those who were least active respectively. Although these significant differences were found in activity-related social support for different groups, the effect sizes of the relationships were small.

\section{Predictors of activity-related social support}

Small but significant correlations were found between adolescent characteristics and activityrelated social support. Correlation analyses demonstrated that age was negatively associated with all sources of support $(r=-.10-r=-.21)$. Ethnicity was negatively associated with mother $(r=-.11)$ and father $(r=-.07)$ logistic support but positively associated with sibling support $(r=.22)$. SES was negatively associated with sibling support $(r=-.12)$ but positively associated with mother and father logistic support $(r=.13, r=.12$ respectively). Gender was negatively associated with father explicit modelling $(r=-.13)$, mother $(r=-.08)$ and father $(r$ $=-.18)$ logistic support and peer support $(r=-.14)$.

Multiple linear regression (see Table 2) was employed to help determine which of the four adolescent characteristics could predict activity-related social support (question two). Age was an important predictor of all types of social support excluding peer support. Ethnicity was a predictor of mother logistic support and sibling support. Gender was a predictor of father explicit modelling and father logistic support, and SES was a predictor of mother and father logistic support. These adolescent characteristics however, only accounted for a small amount of variance in the social support variables. 


\section{Discussion}

Previous research has shown a positive relationship between activity-related social support and adolescents' physical activity ${ }^{12-14}$. However, it is unclear whether perceptions of support differ by sociodemographic characteristics. This study builds on previous activity-related social support research by showing that the amount of social support perceived by adolescents differs by age, gender, ethnicity, SES and physical activity level.

This study demonstrated that younger adolescents perceived more support from all sources than older adolescents, a finding which is supported by Duncan et al. ${ }^{16}$ who reported that younger adolescents perceived greater social support from parents and siblings than older adolescents. This finding is further reinforced by recent longitudinal research demonstrating that peer support and paternal and maternal support decreased during adolescent years ${ }^{17}$. Age was also found to be an important predictor of several types of activity-related support in this study. Taken together with previous research, this suggests that families and parents of older adolescents should be encouraged to provide continued support for physical activity as their child ages.

In this study gender was found to be an important negative predictor of peer support, father explicit modelling and father logistic support. Specifically, boys were found to perceive more activity-related support from several sources than girls, although girls did perceive more mother explicit modelling and sibling support. Findings from previous research examining gender differences have been mixed. For example, Duncan et al. ${ }^{16}$ and Raudsepp et al. ${ }^{25}$ found that girls perceived more logistic support from parents than boys, no gender differences were reported by Davison et al. ${ }^{26}$ but more recently Kirby et al. ${ }^{17}$ found that boys reported 
higher parent and peer support. From the current study we cannot determine why boys tend to perceive more activity-related support but it is possible that boys' physical activity is seen as a higher priority due to culturally prescribed stereotypes around boys and physical activity. Furthermore, previous research has highlighted examples of parents perceiving a greater need to encourage boys to participate in sport/physical activity than girls ${ }^{27}$.

Current results demonstrate that the adolescents achieving the guidelines of physical activity (i.e., those who achieved 5-7 days of at least 60 minutes of physical activity) perceive greater levels of support from all sources, a finding which is consistent with previous qualitative research reporting that active girls reported more parental encouragement than did less active girls $^{28}$. However, as both these studies were cross-sectional the direction of the relationship cannot be determined. Receiving more support may lead to more active children or being more active may lead to receiving more activity-related social support.

In line with current findings several qualitative studies have reported differences in activityrelated support between high and low SES groups albeit in primary school children ${ }^{19}$. Children from middle/high SES primary schools reported that they were encouraged by their parents to take part in physical activity through non-verbal methods which included transport and financial support whereas children from low-SES primary schools reported that their parents were unable to provide this logistic support ${ }^{19}$. Children from middle/high SES primary schools reported more often than children from low-SES schools that they were encouraged by their parents to take part in physical activity through modelling of physical activity behaviour ${ }^{19}$. Children from middle/high SES primary schools also reported participating in physical activity more often with their parents than did children from low SES schools. Another study ${ }^{20}$, reported that parents from high SES groups co-participated in 
physical activity, modelled behaviour and assisted with transport and fee paying, whereas parents from low SES groups appeared to rely on more verbal forms of encouragement to influence their child's physical activity behaviour. This is consistent with previous quantitative research which has shown that low SES youth might be less likely to receive involvement and encouragement from parents than their high-SES counterparts ${ }^{29}$. One explanation for the differences between high and low SES groups could be that low SES families rely more on verbal encouragement due to financial constraints on transport, sports equipment and enrolment in sports club, which families of middle/high SES may not face.

Our findings also demonstrate ethnicity differences in mother and father logistic support with BME adolescents perceiving less support. Within our own qualitative research (unpublished data) we have found that BME groups prioritised religious education in the mosque, which limited after-school physical activity and sports clubs. Furthermore, girls felt that their families did not encourage them to participate in physical activity and sport and some even reported being actively discouraged from taking part. Previous literature has demonstrated that within the South Asian culture physical activity and sport are viewed as relatively insignificant compared with broader lifestyle activities such as family commitments, social mobility and academic achievement ${ }^{30,31}$. This may explain the lower level of logistic support perceived by BME adolescents.

Key strengths of this study include the diverse sample which enabled the examination of ethnicity and SES differences in activity-related social support. Furthermore, the use of a valid multidimensional measure of support enabled the examination of separate sources of support (i.e., family, sibling, peer and mother and father support, and forms of support i.e. modelling, logistic support from mothers and fathers). However, this study is limited by its 
use of a single item questionnaire to assess physical activity. While this may be adequate for our goal of screening or grouping individuals as sufficient or insufficiently active ${ }^{32}$ single item measures lack the scope of multi-item measures to fully capture a complex concept like physical activity and may be associated with greater measurement error. A further limitation of the study is its cross-sectional design which does not allow causality to be examined and the use of a self-report measure of physical activity rather than an objective measure such as accelerometry.

\section{Conclusions}

In summary, activity-related social support differs by, and is predicted by, several adolescent characteristics. Families and peers of adolescents who are female, older (13-14 years of age), BME, low-SES, and less active should be targeted for intervention to encourage and assist them in providing activity-related social support. However, qualitative research needs to be conducted with the families and peers of these identified groups to determine how they can be encouraged to provide more support for physical activity.

\section{Acknowledgements}

The authors wish to acknowledge the Women's Sport and Fitness Foundation for commissioning the research and financial support of the Big Lottery Fund.

\section{References}

1. Hallal PC, Victoria CG, Azevedo MR, Wells JCK. Adolescent physical activity and health: A systematic review. Sports Med. 2006;36(12):1019-1030.

2. Janssen I, LeBlanc AG. Systematic review of the health benefits of physical activity and fitness in school-aged children and youth. Int J Behav Nutr Phys Act. 2010;7:40. 
3. Health Survey for England. Volume 1. Physical activity and fitness. The Information Centre for health and social care 2009. London: The Stationary Office.

4. Dunmith SC, Gigante DP, Domingues MR, Kohl HW. Physical activity change during adolescence: a systematic review and a pooled analysis. Int $J$ Epidemiol. 2011; doi:10.1093/ije/dyq272.

5. Evans JMM, Sheila CM, Kirk A, Crombie IK. Tracking of physical activity behaviours during childhood, adolescence and young adulthood: a systematic review. $J$ Epidemiol. Community Health. 2009;63:9.

6. Brodersen NH, Steptoe A, Boniface DR, Wardle J. Trends in physical activity and sedentary behaviour in adolescence: ethnic and socioeconomic differences. Br J Sports Med. 2007;41:140-144.

7. Nader PR, Bradley RH, Houts RM, McRitchie SL, O’Brien M. Moderate-vigorous physical activity from ages 9 to 15 years. JAMA. 2008;300(3):295-305.

8. Davison K. Activity-related support from parents, peers and siblings and adolescents' physical activity: are there gender differences? J Phys Act Health. 2004;1(4):363-376.

9. Taylor WC, Barabowski T, Sallis JF. Family determinants of childhood physical activity: A social-cognitive model. In Dishman RK (ed). Advances in exercise adherence. Champaign, IL: Human Kinetics; 1994: 319-342.

10. Bandura A. Social foundations of thought and action. A social cognitive theory. PrenticeHall: New Jersey; 1986.

11. Harter S. Developmental processes in the construction of the self. In Yawkey TD, Johnson JE (eds). Integrative process and early socialization: Early to middle childhood. Hillsdale, NJ: Erlbaum; 1988: 45-78.

12. Beets MW, Cardinal BJ, Alderman BL. Parental social support and the physical activityrelated behaviours of youth: A review. Health Edu Behav. 2010; 37(5):621-644. 
13. Edwardson C, Gorely T. Parental Influences on Different Types and Intensities of Physical Activity in Youth: A Systematic Review. Psychol Sport Exerc. 2010;11(6):522-535. 14. Pugliese J, Tinsley B. Parental socialization of child and adolescent physical activity: a meta-analysis. J Fam Psychol. 2007;21(3):331-343.

15. Montemayor R. Parents and adolescents in conflict: All families some of the time and some families most of the time. Journal of Early Adolescence. 1983;3:83-103.

16. Duncan SC, Duncan TE, Strycker LA. Sources and type of social support in youth physical activity. Health Psychol. 2005;24(1):3-10.

17. Kirby J, Levin KA, Inchley J. Parental and peer influences on physical activity among Scottish adolescents: A longitudinal study. J Phys Act Health. 2011;8(6):785-793.

18. Springer AE, Kelder SH, Hoelscher D. Social support, physical activity and sedentary behaviour among $6^{\text {th }}$ grade girls: a cross-sectional study. Int J Behav Nutr Phys Act. 2006; 3:8.

19. Brockman R, Jago R, Fox KR, Thompson JL, Cartwright K, Page AS. 'Get off the sofa and go and play': Family and socioeconomic influences on the physical activity of 10-11 year old children. BMC Public Health. 2009;9:253.

20. Cox M, Schofield G, Kolt GS. Responsibility for children’s physical activity: Parental, child, and teacher perspectives. J Sci Med Sport. 2009;13(1):46-52.

21. The English Indices of Deprivation: Summary, 2007. http://www.communities.gov.uk/documents/communities/pdf/576659.pdf. 22. Centers for Disease Control and Prevention. 2009 Youth Risk Behaviour Surveillance Survey. Available at www.cdc.gov/yrbs. Accessed on 22/02/2010.

23. Brener ND, Kann L, McManus T, Kinchen SA, Sundberg EC, Ross JG. (2002). Reliability of the 1999 Youth Risk Behaviour Survey Questionnaire. J Adolesc Health. 2002;31: 336-342. 
24. Troped PJ, Wiecha JL, Fragala MS, Matthews CE, Finkelstein DM, Kim J, Peterson KE. Reliability and validity of YRBS physical activity items among middle school students. Med Sci Sports Ex. 2007;39(3): 416-425.

25. Raudsepp L. The relationship between socio-economic status, parental support and adolescent physical activity. Acta Paediatr. 2006;95(1):93-98.

26. Davison KK, Schmalz DL. Youth at risk of physical inactivity may benefit more from activity-related support than youth not at risk. Int J Behav Nutr Phys Act. 2006;3:5.

27. MacDonald D, Rodger S, Ziviani J, Jenkins D, Batch J, Jones J. Physical activity as a dimension of family life for lower primary school children. Sport Edu Soc. 2004;9(3):307325.

28. Whitehead S, Biddle S. Adolescent girls' perceptions of physical activity: A focus group study. European Physical Education Review. 2008;14(2):243-262.

29. Vilhjalmsson R, Thorlindsson T. Factors related to physical activity: a study of adolescents. Soc Sci Med. 1998;47(5):665-675.

30. Fleming S. Home and away: Sport and South Asian male youth. Aldershot: Avebury; 1995.

31. Mcguire B, Collins D. Sport, Ethnicity and Racism: the Experience of Asian Heritage Boys. In: Sport, Education and Society. Oxford: Carfax; 1998:79-88.

32. Milton K, Bull FC, Bauman A. Reliability and validity testing of a single-item physical activity measure. Br J Sports Med. 2009;doi:10.1136/bjsm.2009.068395. 
Table 1. Mean sources of support for physical activity

\begin{tabular}{|c|c|c|c|c|c|c|c|}
\hline & GFS & MEM & FEM & MLS & FLS & SS & PS \\
\hline Gender & $\mathrm{N}=1089$ & $\mathrm{~N}=1039$ & $\mathrm{~N}=967$ & $\mathrm{~N}=1055$ & $\mathrm{~N}=973$ & $\mathrm{~N}=1001$ & $\mathrm{~N}=1099$ \\
\hline Boys & 2.58 & 2.49 & 2.78 & 2.75 & 2.83 & 2.65 & 3.01 \\
\hline Girls & 2.58 & 2.54 & $2.61 *$ & $2.64 *$ & $2.56 *$ & 2.71 & $2.85 *$ \\
\hline F value & .004 & 1.33 & 14.96 & 6.39 & 28.69 & 2.02 & 17.79 \\
\hline Effect Size $^{a}$ & 0.00 & 0.01 & 0.015 & 0.006 & 0.029 & 0.002 & 0.016 \\
\hline SES & $\mathrm{N}=915$ & $\mathrm{~N}=874$ & $\mathrm{~N}=811$ & $N=889$ & $\mathrm{~N}=815$ & $\mathrm{~N}=836$ & $\mathrm{~N}=925$ \\
\hline Low & 2.58 & 2.51 & 2.66 & 2.61 & 2.61 & 2.76 & 2.91 \\
\hline High & 2.63 & 2.52 & 2.75 & $2.82 *$ & $2.81 *$ & $2.61 *$ & 2.94 \\
\hline F value & 1.04 & .005 & 3.20 & 17.12 & 12.59 & 11.35 & .59 \\
\hline Effect Size $^{a}$ & 0.001 & 0.000 & 0.004 & 0.019 & 0.015 & 0.013 & 0.001 \\
\hline Ethnicity & $\mathrm{N}=1056$ & $\mathrm{~N}=1004$ & $\mathrm{~N}=938$ & $\mathrm{~N}=1020$ & $\mathrm{~N}=943$ & $\mathrm{~N}=971$ & $N=1064$ \\
\hline White & 2.57 & 2.52 & 2.72 & 2.76 & 2.75 & 2.58 & 2.93 \\
\hline BME & 2.61 & 2.52 & 2.64 & $2.55 *$ & $2.60 *$ & $2.86 *$ & 2.94 \\
\hline F value & .61 & .001 & 2.94 & 18.62 & 7.09 & 40.62 & .007 \\
\hline Effect Size $^{a}$ & 0.001 & 0.000 & 0.003 & 0.018 & 0.007 & 0.040 & 0.000 \\
\hline PA Level & $N=1093$ & $\mathrm{~N}=1044$ & $\mathrm{~N}=971$ & $\mathrm{~N}=1060$ & $\mathrm{~N}=977$ & $\mathrm{~N}=1005$ & $N=1104$ \\
\hline 0-4 days/week & 2.53 & 2.47 & 2.62 & 2.56 & 2.55 & 2.60 & 2.82 \\
\hline 5-7 days/week & $2.64 *$ & $2.57 *$ & $2.78 *$ & $2.85 *$ & $2.85 *$ & $2.76 *$ & $3.07 *$ \\
\hline F value & 7.18 & 4.79 & 11.75 & 40.75 & 34.28 & 13.72 & 43.61 \\
\hline Effect Size $^{a}$ & 0.007 & 0.005 & 0.012 & 0.037 & 0.034 & 0.013 & 0.038 \\
\hline Age & $\mathrm{N}=1092$ & $\mathrm{~N}=1042$ & $\mathrm{~N}=970$ & $\mathrm{~N}=1058$ & $\mathrm{~N}=976$ & $\mathrm{~N}=1004$ & $\mathrm{~N}=1102$ \\
\hline Younger & 2.70 & 2.64 & 2.79 & 2.85 & 2.82 & 2.74 & 2.98 \\
\hline Older & $2.45 *$ & $2.39 *$ & $2.59 *$ & $2.52 *$ & $2.56 *$ & $2.60 *$ & $2.88 *$ \\
\hline F value & 35.74 & 36.49 & 20.93 & 51.77 & 25.31 & 11.10 & 7.20 \\
\hline Effect Size $^{a}$ & 0.032 & 0.034 & 0.022 & 0.047 & 0.025 & 0.013 & 0.007 \\
\hline
\end{tabular}


Table 2. Results from the multiple regression analysis predicting social support

Predictor

B

SE B

$\beta$

$\mathrm{R}^{2}$

General Family Support

Constant

3.30

.23

Age

$-.11$

.02

$-.15 *$

Sibling Support

0.06

Constant

2.73

.22

Age

$-.05$

.02

$-.07 *$

Ethnicity

.23

.06

$.17^{*}$

Peer Support

0.05

Constant

3.03

.21

Gender

$-.13$

.04

$-.10 *$

MEM

3.32

.23

Age

$-.11$

.02

$-.16^{*}$

FEM

0.05

Constant

3.59

.24

Gender

$-.17$

.05

$-.12 *$

Age

$-.10$

.03

$-.14^{*}$

MLS

Constant

3.84

.24

Age

$-.15$

.03

-.19*

SES

.07

.03

$.10 *$

Ethnicity

$-.13$

.06

$-.08^{*}$

FLS

0.08 
Activity-related social support

$\begin{array}{lccc}\text { Constant } & 3.37 & .27 & \\ \text { Gender } & -.26 & .06 & -.16^{*} \\ \text { Age } & -.09 & .03 & -.12^{*} \\ \text { SES } & .09 & .03 & .11^{*}\end{array}$

Note. B indicates unstandardised coefficients; SEB indicates standard error; $\beta$ indicates standardised coefficients; the significance of the variable is denoted by *. * $\mathrm{P}<0.05$. 